\title{
The Performance of Adaptive Approach in Lean and Green Operations
}

\author{
Wei Dong LeOnG ${ }^{1}$, Hon Loong LAM ${ }^{1 *}$, Chee Pin TAN² and SG PONNAMBALAM ${ }^{3}$ \\ ${ }^{1}$ Dept. of Chemical Engineering, University of Nottingham Malaysia Campus, Jalan Broga, 43500 Semenyih, Selangor Darul Ehsan, \\ Malaysia \\ ${ }^{2}$ School of Engineering, Monash University Malaysia, Jalan Lagoon Selatan, 47500 Bandar Sunway, Selangor Darul Ehsan, \\ Malaysia \\ ${ }^{3}$ Faculty of Manufacturing Engineering, University Malaysia Pahang, 26600 Pekan, Pahang Darul Makmur, Malaysia
}

\begin{abstract}
In recent years, the manufacturing sector has been pressured with global warming and resource scarcity. This issue has triggered the industry to seek for solutions to improve the sustainability of their production. Based on literature study, the main components of an organisation consists of manpower, machine, money, material and environment. Thus, the fundamentals need to be addressed to improve the production performance. In this study, an adaptive lean and green approach is presented to identify the priority areas that can improve the organisation performance. Backpropagation algorithm is incorporated into the adaptive model to analyse the dynamic performance of the organisation. However, the input of industry expert is required to prioritise the initial input of the main components. This is relatively important as prioritisation of main components defer from sectors. A case study will be illustrated with the adaptive lean and green model. Operation improvements shall be observed through the implementation of the proposed method.
\end{abstract}

\section{Introduction}

Globalisation has unleased the feasibility and flexibility of manufacturers in global trading. The accessibility of manufactured goods' supply chain has never been so convenient. With the expansion of global market trade, the manufacturers are challenged with monetary fluctuation, political uncertainty, social economic stability and technology advancement (Issa et al., 2010). On top of that, the Sustainable Development Goal (SDG) has been an ambitious initiative advocated by the United Nation Members to strive for global sustainable development (SDG, 2019). The SDG initiative has encouraged many manufacturing players with industry, innovation and infrastructure (SDG 9) and responsible consumption and production (SDG12) to improve global sustainability. By achieving SDG 9 and SDG 12, the competitiveness of manufacturers can be improved through practises such as reduction in production and environmental waste. As the supply chain expands, manufacturers are constantly looking for new ways to maintain the competitiveness with their competitors.

The elimination of production and environmental waste can contribute directly to the organisation's performance. Toyota who is pioneered in lean manufacturing has led a role model in manufacturing sector. Lean manufacturing (LM) is known as the approach that eliminate all non-value-added product or activity in the production process (Womack and Jones,
1994). The LM holds five main principles such as define value, identify value stream, create smooth value flow, implement pull-based production and strive for excellent. On top of that, lean's main principles target seven major wastes (i.e., over-production, waiting, inventory, motion, transportation, over-processing and defects (Leong et al., 2019). Zimmer (2000) highlighted that lean approach can improve the operation performance by $50 \%$ increase in capacity with existing facilities, $50 \%$ improvement in product quality and $60 \%$ reduction in cycle time.

As from the environmental perspective, green processing or green manufacturing is relatively important due to the increasing concern for global warming and climate change. Green manufacturing (GM) is known as business strategy that focuses on profitability through reactive and proactive environmentally friendly operation processes (AbdulRashid et al., 2017). Ferguson and Toktay (2016) stated that GM focuses on closed-loop operation that promote recycling and recuperation practices to reduce waste, capturing product waste while implementing green technologies to reduce pollution. Apart from that, the International Standard Organisation (ISO) has published the Environmental Management System (EMS) standard, known as ISO14001, as a continuous improvement tool to improve the organization's environmental performance (Agan et al., 2013). Leong et al. (2019) mentioned that product life cycle assessment can be used as an evaluation for environmental impact. Jin Kim and

\footnotetext{
*Corresponding author: honloong.lam@nottingham.edu.my
} 
Kara (2012) added that $80 \%$ of the economics, social and environmental impact can be determined during the product or process design stage. As the manufacturing sector is one of the major energy consumers, energy efficiency and management can reduce environmental impact through energy conservation and efficiency practices.

\subsection{Lean and Green Approach in Operations}

The combination of both lean and green $(L \& G)$ approach shows strong commitment in reducing operation and environmental waste. The industry needs to strive a good balance between operation and environment perspective to gain the optimum sustainable output. Galeazzo et al. (2014) stated that organisations that focus in LM approach has received positive influence and effect towards better environmental performance. Chiarini (2014) added that lean tools (i.e., 5S, single minute exchange die (SMED), total productive maintenance (TPM), etc.) will improve environmental performance. On the other hand, Jabbour et al. (2013) has also shown that the implementation of environmental program such as ISO14001 can have positive impact on the organisation performance.

Dües et al. (2013) highlighted that there are overlapping between $\mathrm{L} \& \mathrm{G}$ in terms of people involvement, waste reduction method, supply chain relationship, key performance index (KPI) and tools. L\&G approach share the same objective in improving production, production quality and reduction in production lead time without increasing the environmental emission. Figure 1 demonstrates the relationship and integration between $\mathrm{L} \& \mathrm{G}$.

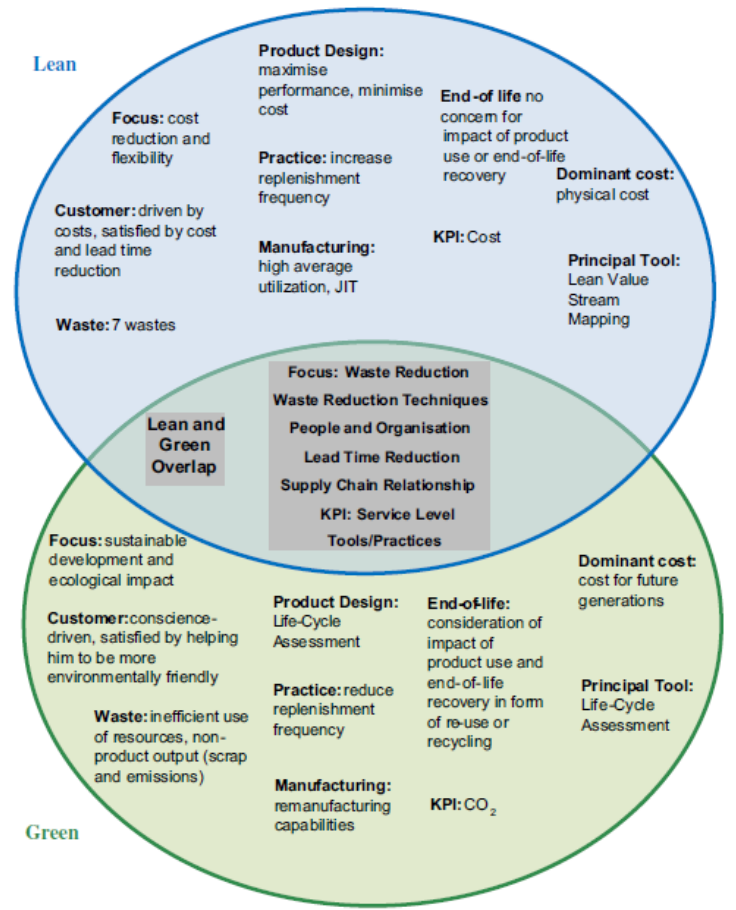

Figure 1. Relationship between lean and green approach (Dües et al., 2013).

Despite there are many established L\&G tools in the market, the application and implementation of $L \& G$ approach has not been effective. As the implementation of $L \& G$ requires experience and time, the lack of competent personnel to implement $L \& G$ practices is the main hurdle for most organisation. Besides that, implementation of $\mathrm{L} \& \mathrm{G}$ practices requires continuous improvement through time to observe the changes in the performance. It is critical to establish a systematic analytic framework that can assist the industry player to make better decision making and improvement action in the organisation. The adaptive approach is developed with the objective in addressing dynamic challenges in the industry. The adaptive approach incorporated with backpropagation algorithm will be used with the $L \& G$ framework to optimise the organisation performance. This study will evaluate the performance of the adaptive L\&G approach using a cogeneration case study.

\section{Lean and Green model}

Figure 2 illustrates the $L \& G$ model. According to Figure 2 , the model started with information collection through a set of questionnaires. The questionnaires will be used to understand the priority and behaviour of the organisation. Then, the critical components will be identified through checklist reflected in Figure 3. Data collection of an organisation is based on the L\&G checklist. Upon completion of data collection, the data will be analysed to generation a lean and green index (LGI). Backpropagation analysis will then further evaluate the performance by comparing the performance outcome with the expected outcome.

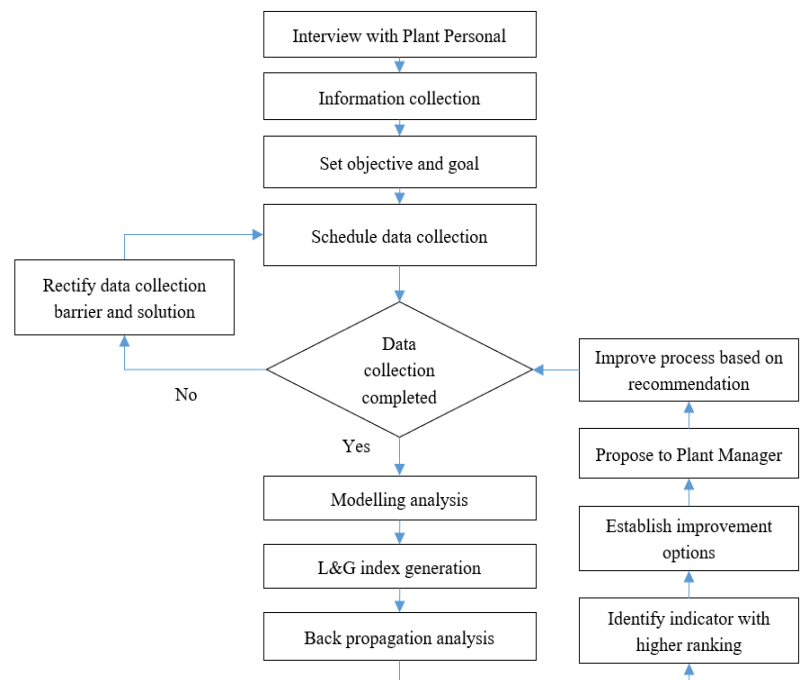

Figure 2. Lean and green model. 


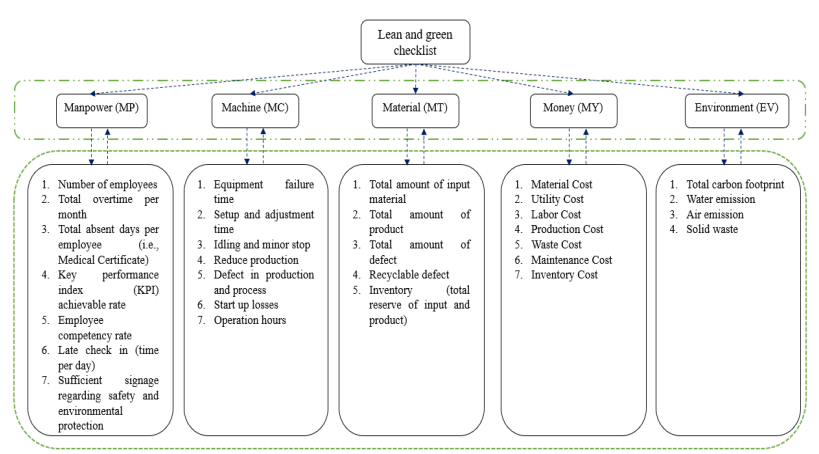

Figure 3. Lean and green checklist.

In this case, analytic hierarchy process (AHP) is used with the L\&G model. The AHP method is a multicriteria decision making (MCDM) tools developed by Saaty (2008). Ngan et al. (2018) highlighted that AHP is a relative measurement that can transform both qualitative and quantitative values into an objective measurement. AHP is used to gather the field expert's opinion on the priority of critical components in the organisation. The priority of components and subcomponents will be represented by a weight value. Figure 4 shows the AHP structure that will be used to perform components prioritisation in an organisation.

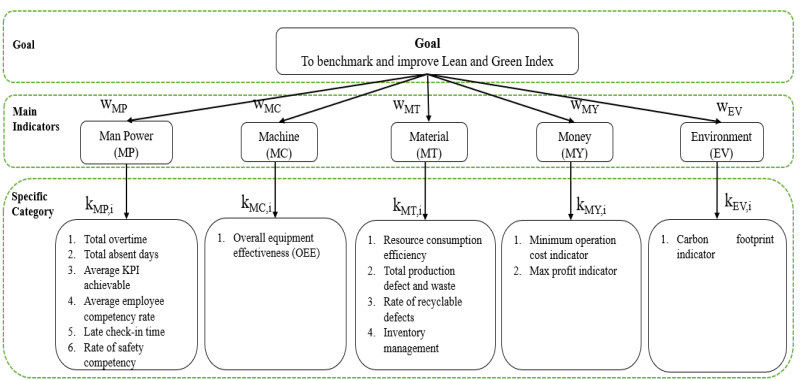

Figure 4. Analytic hierarchy process structure.

This model identified 5 major components and a series of sub-component. The major 5 components (4M1E) are manpower (MP), machine (MC), material (MT), money (MY) and environment (EV). The formation of $4 \mathrm{M} 1 \mathrm{E}$ model considers the fundamental requirement of operation and environmental of an organisation.

\subsection{Lean and green index (LGI)}

The lean and green index (LGI) is generated as a benchmarking tool to evaluate the improvement progress of organisation performance. In this model, the LGI is expressed as:

$$
\begin{array}{r}
\mathrm{LGI}=\mathrm{w}_{\mathrm{MP}} \times \mathrm{MP}+\mathrm{w}_{\mathrm{MT}} \times \mathrm{MT}+\mathrm{w}_{\mathrm{MC}} \times \mathrm{MC}+\mathrm{w}_{\mathrm{MY}} \times \mathrm{MY} \\
+\mathrm{w}_{\mathrm{EV}} \times \mathrm{EV}
\end{array}
$$

where $\mathrm{W}_{M P}, \mathrm{~W}_{\mathrm{MT}}, \mathrm{W}_{\mathrm{MC}}, \mathrm{W}_{\mathrm{MY}}$ and $\mathrm{W}_{\mathrm{EV}}$ represents the weights of the components in obtained from industrialist feedback.

For manpower (MP) index, the employee total overtime ( $\mathrm{MP}_{\mathrm{OT}}, \mathrm{hr} /$ year.pax), employee total absent day $\left(\mathrm{MP}_{\mathrm{AB}}\right.$, day/year.pax), average employee key performance index (KPI) achievable rate $\left(\mathrm{MP}_{\mathrm{KPI}}, \%\right.$ /year.pax), average employee competency rate $\left(\mathrm{MP}_{\mathrm{CR}}, \% /\right.$ year.pax $)$, employee late check-in time, $\left(\mathrm{MP}_{\mathrm{LT}}\right.$, hr/year.pax), employee safety rate ( $\mathrm{MP}_{\mathrm{SC}}, \%$ /year.pax). MP index is expressed as below:

$$
\begin{aligned}
& \mathrm{MP}={ }_{\mathrm{kMP}, \mathrm{OT}} \times \mathrm{MP}_{\mathrm{OT}}+\mathrm{k}_{\mathrm{MP}, \mathrm{AB}} \times \mathrm{MP}_{\mathrm{AB}}+\mathrm{k}_{\mathrm{MP}, \mathrm{KPI}} \times \\
& \mathrm{MP}_{\mathrm{KPI}}+\mathrm{k}_{\mathrm{MP}, \mathrm{CR}} \times \mathrm{MP}_{\mathrm{CR}}+\mathrm{k}_{\mathrm{MP}, \mathrm{LT}} \times \mathrm{MPL}+{ }_{\mathrm{kMP}, \mathrm{SC}} \times \\
& \mathrm{MP}_{\mathrm{SC}}
\end{aligned}
$$

Moving on, the machine (MC) index is calculated as the overall equipment efficiency (OEE) which take into consideration of the availability of equipment (A), performance efficiency $(\mathrm{P})$ and rate of quality product (Q).

$A=\frac{\text { Planned operation time- }-\left(\begin{array}{c}\text { equip failure time- } \\ \text { set up time loss }\end{array}\right)}{\text { Planned operation time }}$

$P=\frac{\text { Total processed amount } \times \text { Ideal production rate }}{\text { Actual operation time }}$

$Q=\frac{\text { Processed amount }- \text { Defect amount }}{\text { Processed amount }}$

$\mathrm{MC}$ is expressed as below:

$\mathrm{MC}=\mathrm{A} \times \mathrm{P} \times \mathrm{Q}$

The material (MT) index is calculated based on resource consumption efficiency $\left(\mathrm{MT}_{\mathrm{RE}}\right)$, product to defect indicator, $\left(\mathrm{MI}_{\mathrm{DI}}\right)$ rate of recyclable defects $\left(\mathrm{MT}_{\mathrm{RD}}\right)$ and inventory $\left(\mathrm{MT}_{\mathrm{IN}}\right)$.

$$
\begin{aligned}
& M T_{R E}=\frac{\text { Total amount of product }}{\text { Total amount of material input }} \\
& M T_{D I}=\frac{\text { Total amount of product-Total product defects }}{\text { Total amount of product }} \text { (8) } \\
& M T_{R D}=\frac{\text { Total amount of defects }- \text { Recycable defects }}{\text { Total amount of defects }} \\
& \text { (Minimum monthly material input } \\
& M T_{I N}=\frac{\text { +average monthly production })}{\text { (Average monthly input material }} \\
& \text { +maximum monthly production ) }
\end{aligned}
$$

Thus, MT is calculated as below:

$$
\begin{aligned}
& M T=k_{M T, R E} \times M T_{R E}+k_{M T, D I} \times M T_{D I}+k_{M T, R D} \times \\
& M T_{R D}+k_{M T, I N} \times M T_{I N}
\end{aligned}
$$

As for money (MY) index, the index is represented by total operation cost, $\mathrm{MY}_{\mathrm{OC}}$ and total profit, $\mathrm{MY}_{\mathrm{TP}}$ that reflects the core financial consideration in an organisation.

$$
\begin{aligned}
& M Y_{O C}=\frac{\text { Min operation cost } / \text { unit of product }}{\text { Avg operation cost } / \text { unit of product }} \\
& M Y_{T P}=\frac{\text { Maximum profit cost } / \text { unit of product }}{\text { Average profit cost } / \text { unit of product }}
\end{aligned}
$$

Thus, MY is calculated as below: 
$M Y=k_{M Y, O C} \times M Y_{O C}+k_{M Y, T P} \times M Y_{T P}$

Lastly, the environmental index (EV) mainly reflects on carbon dioxide $\left(\mathrm{EV}_{\mathrm{CO} 2}\right)$, water emission $\left(\mathrm{EV}_{\mathrm{ww}}\right)$ and solid waste $\left(\mathrm{EV}_{\mathrm{SW}}\right)$.

$$
\begin{aligned}
& E V_{C O 2}=\frac{\text { min } \mathrm{CO} 2 \text { emission } / \text { total production }}{\text { avg CO2 emission } / \text { total production }} \\
& E V_{W W}=\frac{\text { min water emission } / \text { total production }}{\text { avg water emission } / \text { total production }} \\
& E V_{S W}=\frac{\text { min solidwaste } / \text { total production }}{\text { avg solidwaste } / \text { total production }}
\end{aligned}
$$

Thus, EV is calculated as below:

$$
E V=k_{E V, C O 2} \times E V_{C O 2}+k_{E V, W W} \times E V_{W W}+
$$$$
k_{E V, S W} \times E V_{S W}
$$

\subsection{Adaptive approach}

The adaptive approach in $L \& G$ context is incorporated with backpropagation (BP) algorithm. The BP algorithm is an algorithm that was fully based on the reverse mode of differentiation (Griewank, 2012). This method is popularised by Rumelhard et al. (1986) with the application of neural network to learn representation. The application of the adaptive approach is to overcome the limitation of static model. A static analytic model is good in predicting model, but it is unable to cope with dynamic challenges in the real world.

With the application of BP, continuous improvement in dynamic situation can be carried with the updating algorithm through depth of time. Figure 5 demonstrates the framework of adaptive approach.

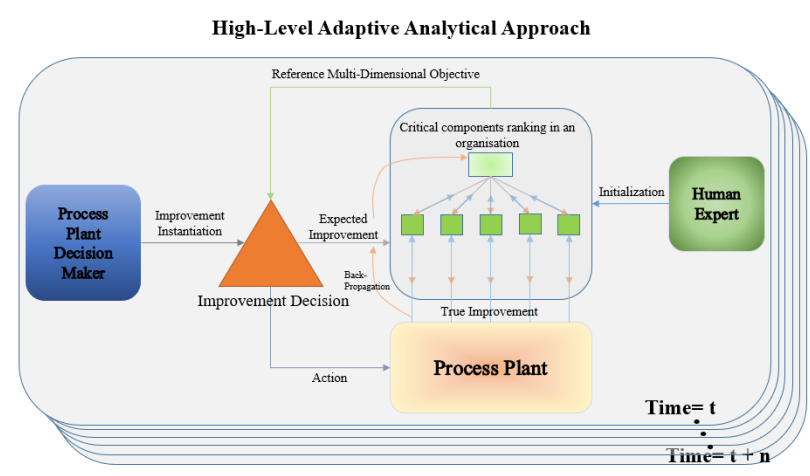

Figure 5. Adaptive analytic approach.

The adaptive approach reflects the output from the process plant by comparing with the expected improvement criteria. Then, the approach will adjust the improvement priority of the critical components in the organisation. As industry priority varies according to sector, the 'human expert' input will depend on the nature of the industry.

The BP method utilises the update rules to update the LGI. The error, also known as the different between actual and expected LGI, will be backpropagated within the model representing in Eqn (1).

$$
E=\frac{1}{2}\left(L G I_{\text {actual }}-L G I_{\text {expect }}\right)^{2}
$$

Where $\mathrm{E}$ is the error, $\mathrm{LGI}_{\text {expect }}$ is the quantified improvement target but not implemented. The LGI $\mathrm{Latual}_{\text {is }}$ measured after the improvement is implemented. A gradient descent with chain rule is implemented for next layer

$$
w_{i+1}=w_{i}-\eta \frac{E_{i}-E_{i-1}}{w_{i}-w_{i-1}}
$$

$\mathrm{W}_{i}$ is the weight of the 5 main components on the current month. $\mathrm{W}_{i+1}$ is the new weight (target) for the next time step. A learning rate, $\eta$ of 0.05 is used in to update the weight indicated above.

$$
k_{i+1}=k_{i}-\eta \frac{E_{i}-E_{i-1}}{w_{i}-w_{i-1}} \times \frac{w_{i}-w_{i-1}}{k_{i}-k_{i-1}}
$$

$\mathrm{k}_{i}$ indicates the weight of each indicator under the 5 main components, where $i$ is the time step. The error will be a transfer down to the analytic model using the chain rule and update the weight for each time step.

\section{Case Study}

A cogeneration (combine heat and power) plant that produces electricity and steam by consuming natural gas is demonstrated by implementing the adaptive L\&G approach. Figure 6 illustrates the boundary of the case study.

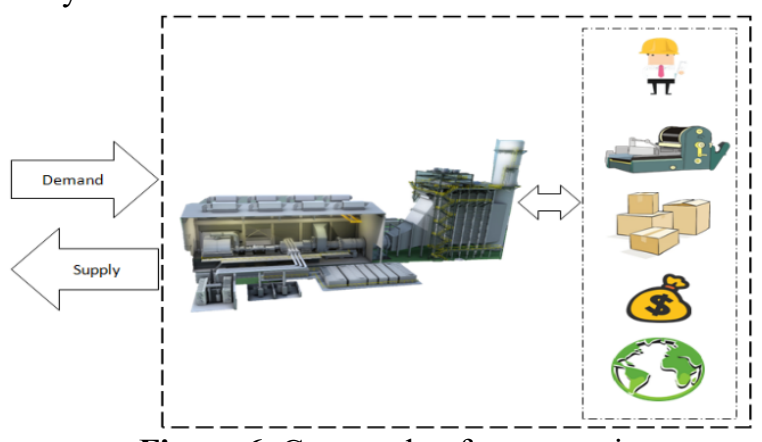

Figure 6. Case study of cogeneration.

Below indicates the specification of the case study:
a. Main fuel source
: Natural Gas
b. Max electricity generation
: $6.5 \mathrm{MW}$
c. Maximum steam recovery
: 16tonnes/hr
d. Total operation days
: 351 days
e. Total operation hours
: 8424 hours
f. Annual shutdown days
: 14 days

\subsection{Results and discussions}

In this case study, the operation data has been collected from year 2015 to year 2018. Based on the L\&G model, AHP indicates the priority of the $4 \mathrm{M} 1 \mathrm{E}$ as MY with $26.1 \%$, EV with $21.5 \%$, MP with $18.7 \%$, machine with $18.2 \%$ and MT with $15.5 \%$. The industry expert categorised MY as the most critical component in the operation.

Figure 7 illustrates the overall performance of individual components of the cogeneration plant. Each 
component has shown progressive improvement since year 2015. Based on data collection, the improvement of employee competency rate and KPI has reflected improvement of MP index since year 2015. Figure 8 reflects the improvement trend of MP.

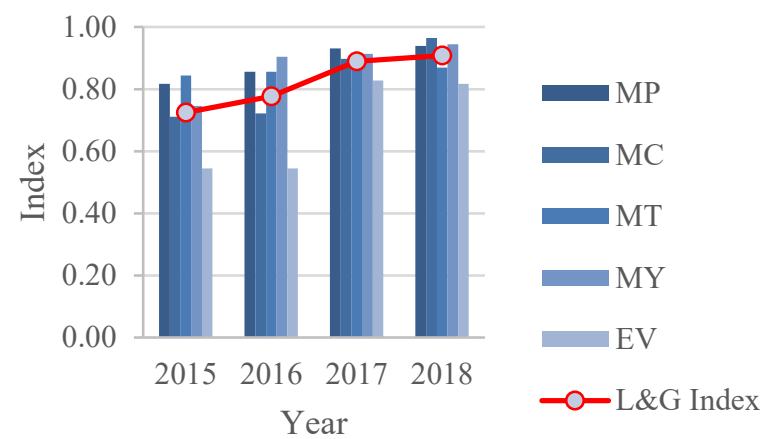

Figure 7. Overall performance of $L \& G$ index.

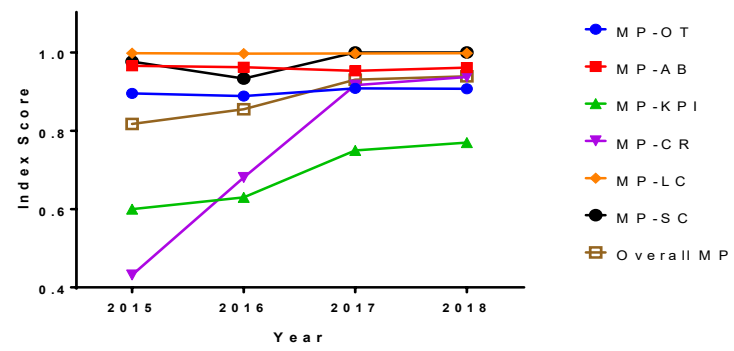

Figure 8. Manpower (MP) indicator.

From Figure 9, it can be observed that performance of the cogeneration plant has improved since year 2015. Based on the collected data, MC is mainly affected by the supply chain factor and the competency of employees in handling the task. In year 2017, the organisation achieves the world-class performance benchmark of $85 \%$.

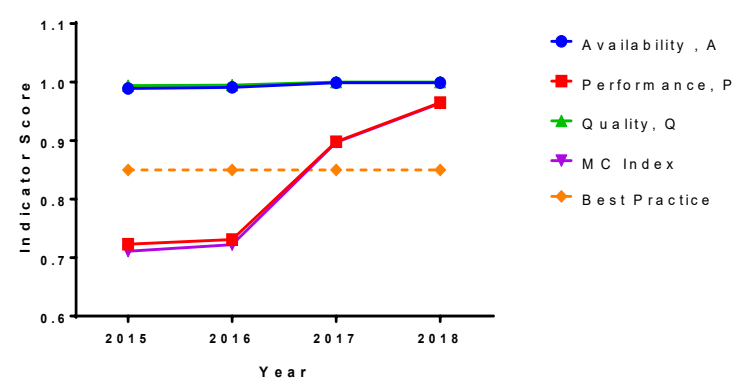

Figure 9. Machine (MC) indicator.

Moving on, Figure 10 reflects the performance of material management. In this study, the cogeneration plant does not require storage of feedstock material (i.e., natural gas) and the output of the process will be produced based on demand.

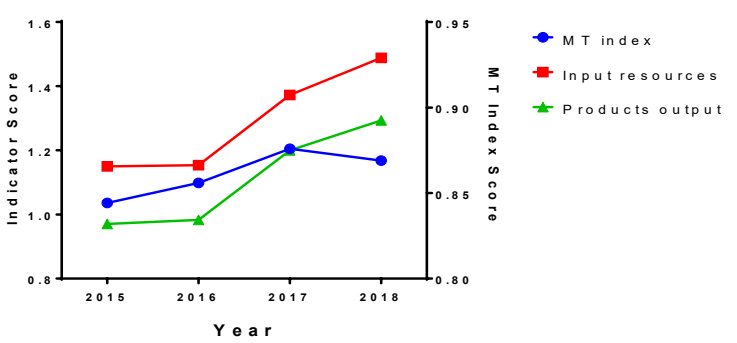

Figure 10. Material (MT) indicator.

MY is one of the most critical components in every organisation that reflects the profitability of the operation. Based on Figure 11, it shows that the operation cost is managed effectively with an average index of higher than 0.9 . The profit is mainly due to fluctuation of prices of raw material and product.

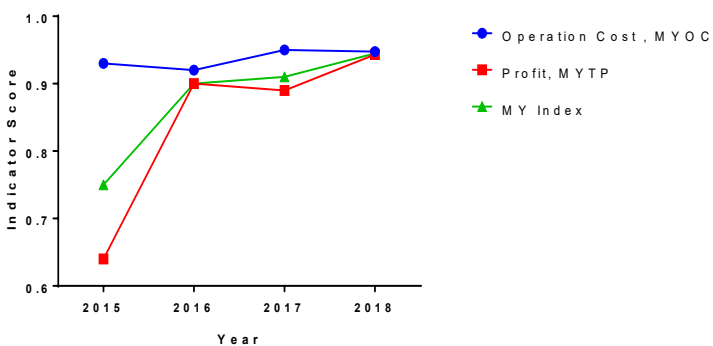

Figure 11. Money (MY) indicator.

From the EV perspective, the emission has a lower index value due to incompetent operation control and supply demand of energy. The demand of energy will have a direct influence on the combustion efficiency that will reflected on the emission. Figure 12 reflects that EV has been progressively improving over the years.

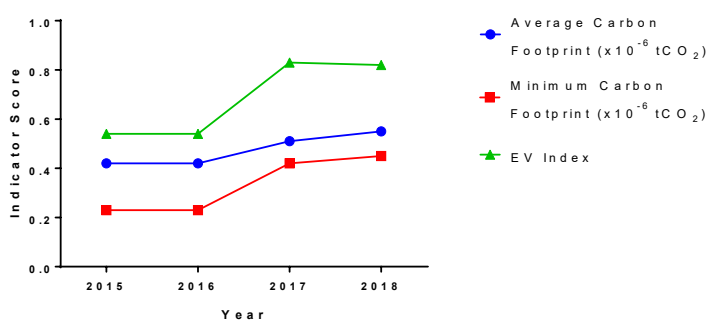

Figure 12. Environmental (EV) indicator.

In this study, the targeted LGI is determined as 0.96 . The BP method has been implemented in the process for 7 months starting in July 2018. Figure 13 shows the response in BP method in achieving the desire target. Besides that, Figure 14 indicates the BP approach of 4M1E. Based on the BP performance, the performance of BP has managed to close the gap between actual and expected targets with a deviation of $1.3 \%$. On top of that, the BP algorithm explores 4M1E in September and October for improvement. The BP model manages to converge in November where the weightage is very close to their initial value obtained from the industry expert. 


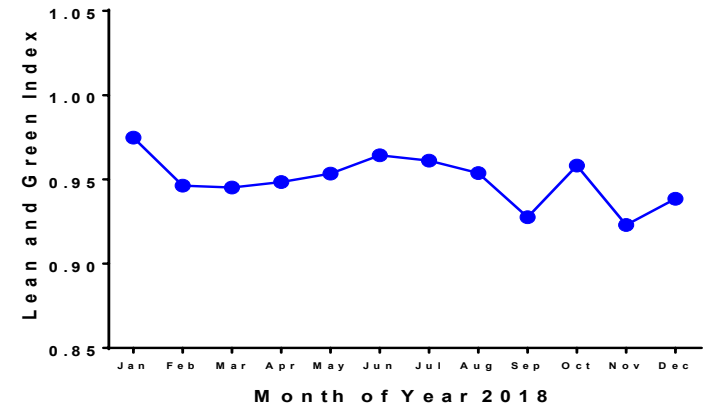

Figure 13. Lean and green index for year 2018.

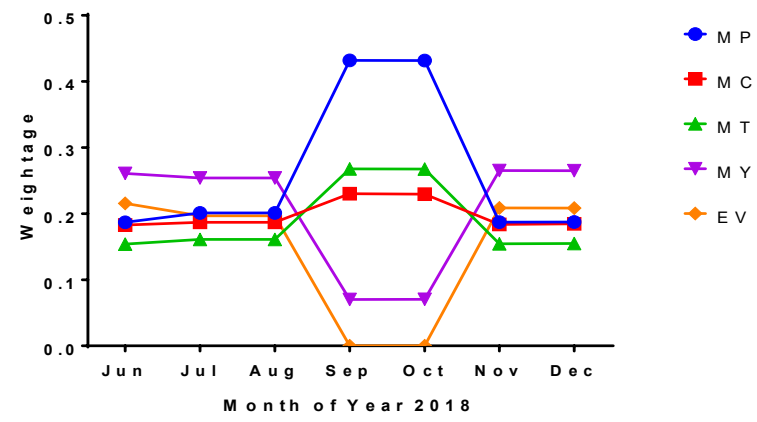

Figure 14. Optimisation on 4M1E.

\section{Conclusion}

This study reflects the enhancement of adaptive lean and green model in cogeneration plant. The model aims to provide a time-dependant multi criteria decision making tool for the industry player to make better decisions. Based on the outcome of the case study, the adaptive model can close the gap between the targeted and actual lean and green index by $1.3 \%$. Obvious improvement can be seen as the lean and green practises are implemented in the organisation. The adaptive model will continuously evaluate the priority of the components stated in the model to reduce the deviation between actual and expected outcome. Future work can be extended to improve the complexity of the adaptive model to cope with multi-interrelated components problems (i.e. continuous processing plant).

\section{Acknowledgements}

The authors would like to acknowledge financial support from the Ministry of Higher Education (FRGS/1/2016/TK03/MUSM/01/1). Research funding and support from Newton Fund and the EPSRC/RCUK (Grant Number: EP/PO18165/1) is also gratefully acknowledged.

\section{References}

Abdul-Rashid, S. H., N. Sakundarini, R. A. Raja Ghazilla and R. Thurasamy; "The Impact of Sustainable Manufacturing Practices on Sustainability Performance: Empirical Evidence from Malaysia", Int. J. of Oper. \& Production Mgmt., 37 (2), 182-204 (2017)

Agan, Y., M. Acar, and A. Borodin; "Drivers of Environmental Processes and Their Impact on
Performance: a Study of Turkish SMEs," J. Cleaner Prod., 51, 23-33 (2013)

Ferguson, M. and L. Toktay; "The Effect of Competition on Recovery Strategies," Prod. and Oper. Mgmt, 15(3), 351-368 (2009)

Galeazzo, A., A., Furlan and A. Vinelli; "Lean and Green in Action: Interdependencies and Performance of Pollution Prevention Projects," J. Cleaner Prod., 85, 191-200 (2014)

Issa, T., V. Chang, and T. Issa; "Sustainable Business Strategies and PESTEL Framework," GSTF Int. J. Comput., May, 1-8 (2010)

Jabbour, C., A. Jabbour, K. Govindan, A. Teixeira, and W. Freitas; "Environmental Management and Operational Performance in Automotive Companies in Brazil: the Role of Human Resource Management and Lean Manufacturing," J. Cleaner Prod, 47, 129-140 (2013)

Kim, S. J. and S. Kara; "Impact of Technology on Product Life Cycle Design: Functional and Environmental Perspective," $19^{\text {th }}$ CIRP Conference on Life Cycle Engineering, D. A. Dornfeld and B. S. Linke eds, pp. 1-2, Springer, New York City, U.S.A. (2012)

Leong W. D., H. L. Lam, W. P. Q. Ng, C. H. Lim, C. P. Tan, and S. G. Ponnambalam; "Lean and Green Manufacturing - a Review on its Applications and Impacts," Process Integr. Optim. Sustain, 3, 5-23 (2019)

Mittal V. K and K. S. Sangwan; "Prioritizing Drivers for Green Manufacturing: Environmental, Social and Economic Perspectives," Procedia CIRP, 15, 135-140 (2014)

Saaty T. L; Decision Making with the Analytic Hierarchy Process (2008)

SDG, Sustainable Development Goals: Sustainable Development Knowledge Platform. https://sustainabledevelopment.un.org/?menu=1300 (accessed 4.29.19)

Womack, J. P. and D. T. Jones; "From Lean Production to the Lean Enterprise," Harvard Business Review, 72, 93-103 (1994)

Zimmer, L.; "Get Lean to Boost Profits," Form. Fabr., 7 (2), 36- 44 (2000) 